\title{
Altering the response of intracellular reactive oxygen to magnetic nanoparticles using ultrasound and microbubbles
}

\author{
Fang Yang ${ }^{1 *}$, Mingxi $\mathrm{Li}^{1}$, Huating Cui ${ }^{1}$, Tuantuan Wang ${ }^{1}$, Zhongwen $\mathrm{Chen}^{2}$, Lina Song ${ }^{1}$, Zhuxiao $\mathrm{Gu}^{3}$, \\ Yu Zhang ${ }^{1}$ and Ning $\mathrm{Gu}^{1,4^{*}}$
}

Engineered iron oxide magnetic nanoparticles (MNPs) are one of the most promising tools in nanomedicine-based diagnostics and therapy. However, increasing evidence suggests that their specific delivery efficiency and potential long-term cytotoxicity remain a great concern. In this study, using $12 \mathrm{~nm} \gamma-\mathrm{Fe}_{2} \mathrm{O}_{3}$ MNPs, we investigated three types of uptake pathways for MNPs into HepG2 cells: (1) a conventional incubation endocytic pathway; (2) MNPs co-administrated with microbubbles under ultrasound exposure; and (3) ultrasound delivery of MNPs covalently coated on the surface of microbubbles. The delivery efficiency and intracellular distribution of MNPs were evaluated, and the cytotoxicity induced by reactive oxygen species (ROS) was studied in detail. The results show that MNPs can be delivered into the lysosomes via classical incubation endocytic internalization; however, microbubbles and ultrasound allow the MNPs to pass through the cell membrane and enter the cytosol via a non-internalizing uptake route much more evenly and efficiently. Further, these different delivery routes result in different ROS levels and antioxidant capacities, as well as intracellular glutathione peroxidase activity for HepG2 cells. Our data indicate that the microbubble-ultrasound treatment method can serve as an efficient cytosolic delivery strategy to minimize long-term cytotoxicity of MNPs.

\section{INTRODUCTION}

Various nanomaterials or nanoparticles have emerged as powerful diagnostic imaging agents and drug delivery carriers. Several recent studies have demonstrated the potential of these materials in the development of multifunctional probes with both imaging and therapeutic capabilities [1,2]. In particular, superparamagnetic iron oxide nanoparticles have been successfully used as delivery platforms for bioseparation, magnetic drug delivery, and magnetic resonance imaging (MRI) contrast agents, as well as for magnetic hyperthermia of tumor treatment [3-6]. Because of their relatively good biocompatibility and wellknown surface modification capabilities, they have also been designed as multitasking systems that possess synergistically enhanced properties such as better imaging resolution and sensitivity [7], molecular recognition capabilities [8], and stimulus magnetic responsive drug delivery [9]. They also have potential applications in cancer theranostics, including non-invasive visualization of molecular markers for early stages of cancer and the targeted delivery of therapeutic agents to tumor cells with a concurrent, substantial reduction of deleterious side effects.

However, nanoparticles must cross the cell plasma membrane to enter the cells, after which they need to gain access to the appropriate organelle where the biological target is located (e.g., cytoplasm, nucleus, mitochondria, etc.) [10]. Therefore, safe and efficient localization of nanoparticles in the cells for biomedical functions are needed. Generally, incubation with cells is the conventional nanoparticle internalization approach, in which the delivery efficiency significantly depends on the size, shape, composition, charge, surface chemistry, etc. $[11,12]$. In the case of cancer cells, it is not easy to deliver the nanoparticles to intracellular locations efficiently because cancer cells can recognize and expel extracellular components by using specialized transporters [13]. The efficiency of transporting nanoparticles into a cell is inherently challenging due to the difficulties in engineering nanoparticles that can repeatedly penetrate various membranes of cells. In addition, engineered nanoparticles are not inherently benign, and they may affect biological behaviors at the cellular, subcellular, and protein levels [14]. For example, if nanoparticles enter the

\footnotetext{
${ }^{1}$ State Key Laboratory of Bioelectronics, Jiangsu Key Laboratory for Biomaterials and Devices, School of Biological Science and Medical Engineering, Southeast University, Nanjing 210096, China

${ }^{2}$ Mechanobiology Institute, National University of Singapore, Singapore 117411, Singapore

${ }^{3}$ Department of Chemical Engineering, University of Florida, Gainesville, FL 32611, USA

${ }^{4}$ Collaborative Innovation Center of Suzhou Nano Science and Technology, Suzhou 215123, China

* Corresponding authors (emails: yangfang2080@seu.edu.cn (Yang F); guning@seu.edu.cn (Gu N))
} 
enzymatic environment of the lysosomes, they could have an impact on cell cycle, cell signaling, apoptosis, oxidative stress, and inflammation $[15,16]$. Therefore, in order to achieve proper cell response and higher delivery efficiency, it is important to find new strategies for targeting magnetic nanoparticles (MNPs) to specific intracellular compartments.

Some improved approaches, including disruption of endosomes, direct microinjection, electroporation, and conjugation of natural cell-penetrating/fusogenic chaperones to nanomaterials, have been utilized to enhance nanoparticle endocytic uptake with minimal toxicity [17-19]. Among these novel approaches, ultrasound (US) in combination with microbubbles (MBs) has received increasing interest as an activation mechanism for carrier delivery because of its advantages in spatial and temporal control of compound release [20-23]. The basic principle of ultrasound-mediated intracellular nanoparticle delivery technique is the microbubble response to the ultrasound. When a traveling low-amplitude ultrasonic wave is absorbed by compressible microbubbles, the microbubbles will produce far greater echo forces [called ultrasound radiation force (USRF)]. After pulses of many cycles, the USRF may push MBs to the targeted cells [24]. When a high-amplitude ultrasonic wave interacts with MBs, small pores in the cell membrane can form by a process called sonoporation $[25,26]$. The transit pores allow transport of compounds into the cytoplasm of living cells [27]. These unique characteristics make microbubble-mediated ultrasound a compelling and versatile technology for nanoparticle delivery into cells.

However, proinflammation and reactive oxygen species (ROS)-induced cell-signaling cytotoxicity remain a great concern in nanomedicine-based diagnostics and therapy [28]. Oxidative stress in particular has been repeatedly reported as one of the primary mechanisms by which metal oxide nanoparticles may cause adverse biological effects $[29,30]$. ROS may be the underlying genotoxicity mechanism for the MNPs, and hence, it has to be balanced according to non-invasive tumor imaging and drug delivery applications $[31,32]$. It has been widely reported that intracellular ROS production is considerably affected by the size and surface chemistry of MNPs [33,34]. Additional studies that quantify the ROS toxicity caused by MNPs in specific subcellular compartments are still needed. Moreover, the relationship between the intracellular delivery pathway and the corresponding ROS response remains unclear. The aim of this work is as follows: 1) to investigate the cellular uptake of different MNPs and their intracellular location by comparing the incubation pathway with microbubble-ultrasound approaches and 2) to assess the intracellular ROS levels, the antioxidant capacity and activities of glutathione peroxidase (GPx) to MNPs in different cellular uptake pathways. Aminopropyltriethoxysilane (APTS)-modified $\gamma-\mathrm{Fe}_{2} \mathrm{O}_{3} \mathrm{MNPs}$ were chosen as the delivery nanoparticles in the experiment. Three administration methods were employed for $\gamma-\mathrm{Fe}_{2} \mathrm{O}_{3}$ delivery into HepG2 tumor cells: 1) MNP incubation with cells, 2) MNPs and microbubbles co-administrated under ultrasound exposure, and 3) MNP-coated microbubbles interacting with cells under ultrasound treatment. The corresponding samples, denoted as MNPs-Cell, MNPs-MBs-US-Cells, and MNPs@MBsUS-Cells, respectively, were evaluated.

\section{RESULTS}

\section{Characterization of nanoparticles and microbubbles}

Transmission electron microscopy (TEM) images and the hydrodynamic size distribution of APTS-modified $\gamma-\mathrm{Fe}_{2} \mathrm{O}_{3}$ are shown in Figs 1a and d. The mean hydrodynamic size was $76.0 \mathrm{~nm}$. The TEM size was $12.2 \mathrm{~nm}$. The zeta potential of the APTS-modified $\gamma-\mathrm{Fe}_{2} \mathrm{O}_{3}$ was positive $(+10.5 \mathrm{mV})$ because of the amino group on the surface. The zeta potential of the MNPs@MBs was negative $(-29.3 \mathrm{mV})$. The optical bright-field image and size distribution of microbubbles with unbound and bound nanoparticles are also shown in Figs $\mathrm{lb}$ and $\mathrm{e}, \mathrm{c}$ and $\mathrm{f}$, respectively. The morphology images show that the microbubbles have a spherical shape with a mean diameter of $2.15 \mu \mathrm{m}$. TEM images (insets of Figs $1 \mathrm{~b}$ and c) of microbubbles with unbound and bound nanoparticles clearly show that the nanoparticles are modified on the surfaces of microbubbles. When nanoparticles are covalently bonded on the surfaces of the microbubbles, there is no significant change in the morphology and mean diameter. The concentration of MNPs within the microbubbles is determined to be $20.3 \times 10^{-5} \mu \mathrm{g}$ per MB by the UVvis spectrophotometer method. The MNP concentration of $1 \times 10^{5}$ microbubbles was $20.3 \mu \mathrm{g}$, the same concentration as that of the MNPs used with the incubation and co-administration treatments.

\section{Acoustic response of nanoparticle-coated microbubbles}

In general, at lower acoustic pressures, the microbubbles can be located close enough to the targets by USRF. At higher acoustic pressures, microbubble-mediated ultrasound can increase cell permeability as a result of pore formation within the cell membrane during sonoporation [35]. The ultrasonic backscatter behavior of microbubbles with unbound and bound MNPs is shown in Fig. 2a. The radiofrequency $(\mathrm{RF})$ echo signals and their power spectra were compared. The microbubbles coated with MNPs 

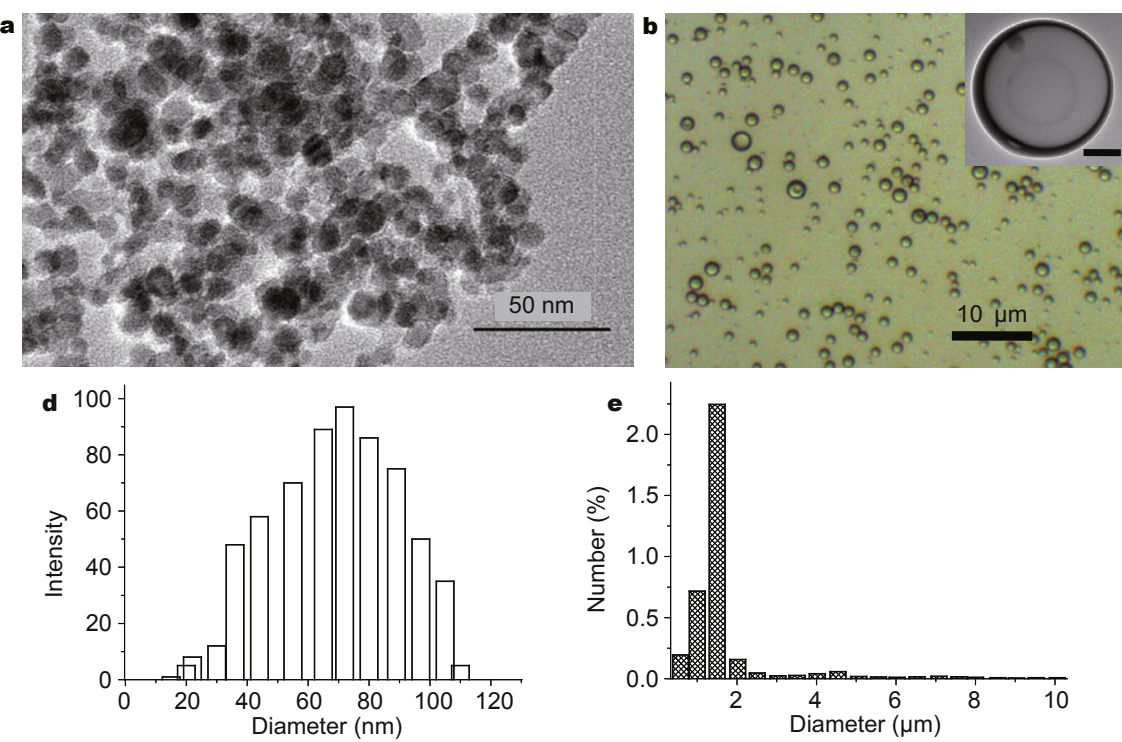
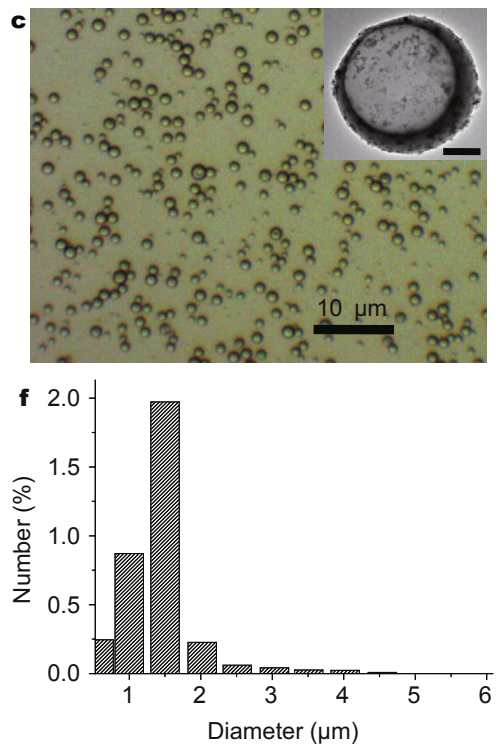

Figure 1 (a) TEM image of $\gamma-\mathrm{Fe}_{2} \mathrm{O}_{3}$ nanoparticles and (d) the mean hydrodynamic size of $\gamma-\mathrm{Fe}_{2} \mathrm{O}_{3}$. The microscopy images and mean size distribution of microbubbles with (b, e) unbound and (c, f) bound $\gamma$ - $\mathrm{Fe}_{2} \mathrm{O}_{3}$ nanoparticles. Insets in $(b, c)$ are the TEM images of microbubbles with unbound and bound $\gamma-\mathrm{Fe}_{2} \mathrm{O}_{3}$ nanoparticles, and the scale bar is $500 \mathrm{~nm}$.
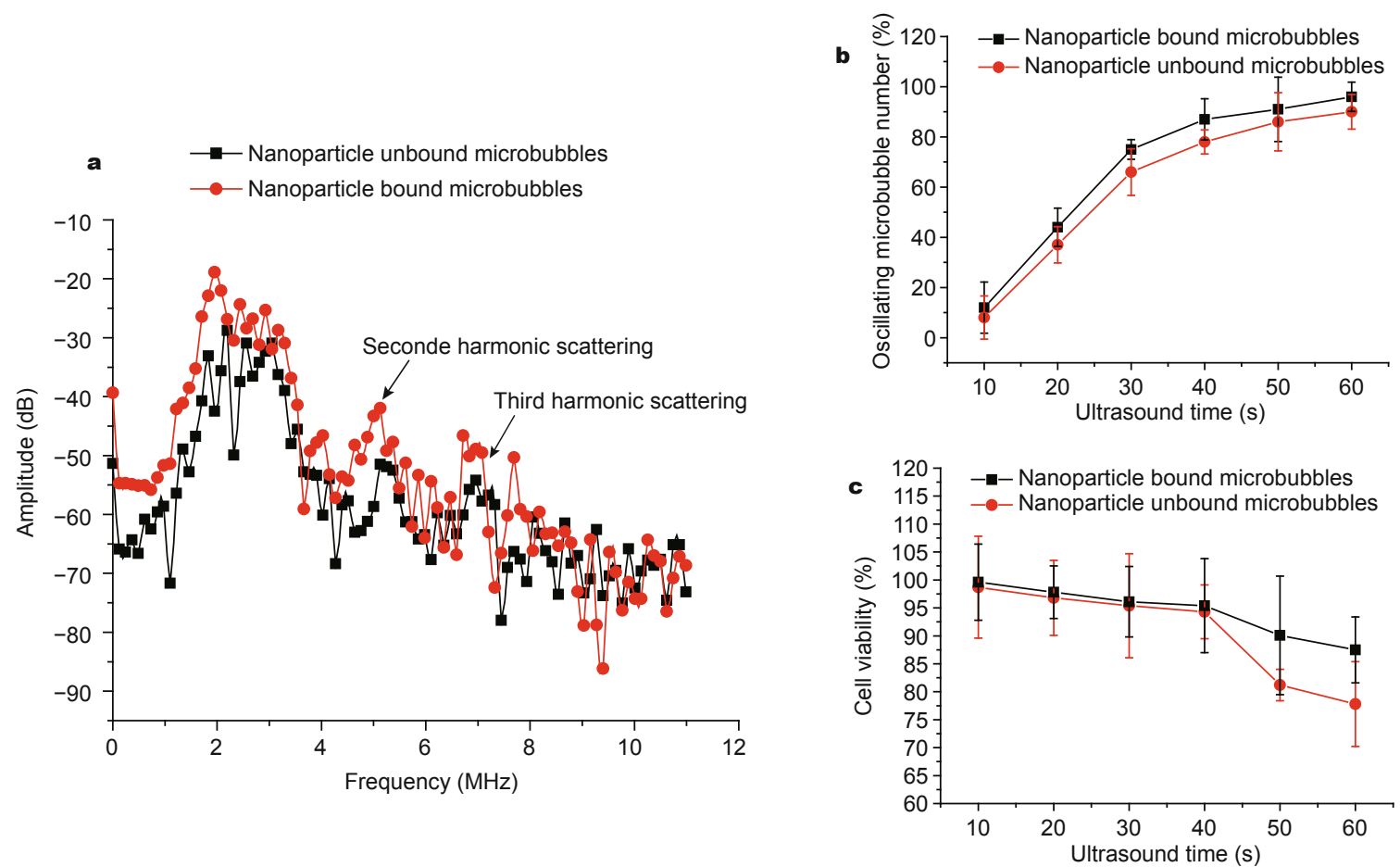

Figure 2 (a) The statistic results of the amplitudes for the fundamental, second, and third harmonics. The $\gamma-\mathrm{Fe}_{2} \mathrm{O}_{3}$-coated microbubbles possess stronger (about 5 or $8 \mathrm{~dB}$ ) second and third harmonics than the microbubbles without nanoparticles. (b) Disrupted oscillating microbubble detection $v s$. ultrasound exposure time for microbubbles with unbound and bound nanoparticles. (c) Cell viability after ultrasound treatment with microbubbles with unbound and bound nanoparticles. 
had higher second and third harmonics than microbubbles without MNPs, which means that microbubbles with bound nanoparticles are more sensitive to nonlinear acoustic echoes. Thus, in response to the compression and rarefaction phases of an ultrasonic pressure wave, microbubbles will expand, contract, or oscillate in a nonlinear fashion. Based on this characteristic, the fraction of oscillating bubbles with increasing exposure time is shown in Fig. 2b. The results show that the microbubbles with unbound MNPs have a lower fraction of oscillating bubbles than microbubbles with bound MNPs under the same ultrasound exposure time. Under $1 \mathrm{MHz}$ frequency and 0.25 MPa acoustic pressure, over $80 \%$ of the microbubbles show disrupted oscillatory behavior after $40 \mathrm{~s}$ ultrasound exposure. In fact, longer ultrasound exposure time can lead to a greater fraction of oscillating bubbles. Nonetheless, when treated with different ultrasound exposure times $(10,20$, $30,40,50$, and $60 \mathrm{~s}$ ) after $12 \mathrm{~h}$ incubation, the cell viability decreases (Fig. 2c). Our previous results also showed that a higher acoustic threshold resulted in the death of cells [36]. Thus, to ensure the ultrasonic responsive properties and sufficient viability of cells, the ultrasound exposure time in the experiment was chosen as $40 \mathrm{~s}$ under a frequency of 1 $\mathrm{MHz}$ and $0.25 \mathrm{MPa}$ acoustic pressure.

\section{Intracellular nanoparticle distribution and concentration}

The distribution of MNPs within HepG2 cells was verified using Prussian blue dying microscopy imaging and TEM images, as shown in Fig. 3. The intracellular levels of MNPs are qualitatively proportionate to the total amount of MNPs incubated with the cells as determined through intracellular iron analysis, as shown in Table S1. After treatment using different approaches, and $12 \mathrm{~h}$ culture with the cells, the MNP delivery efficiencies of MNPs-Cells, MNPsMBs-US-Cells, and MNPs@MBs-US-Cells are $71.66 \pm$ $2.68 \%, 82.34 \pm 5.01 \%$, and $88.76 \pm 4.33 \%$, respectively. Figs $3 \mathrm{a}, \mathrm{a}_{1}$, and $3 \mathrm{~d}, \mathrm{~d}_{1}$ indicate that MNPs are internalized into the cells after direct incubation. However, the distribution of MNPs is heterogeneous and the majority of them are aggregated (arrows). For the ultrasound and microbubble treatment groups, the Prussian blue dying and TEM results (Figs 3b, c, e and $\mathrm{f}$ ) show that more MNPs are delivered into the cells. It seems that MNPs are uniformly distributed on the inner sides of the cells (arrows). When the MNPs are loaded on the microbubbles, the delivery efficiency of MNPs reaches its highest value (Figs $3 \mathrm{c}$ and $\mathrm{f}$ ). A possible explanation may be the sonoporation process, in which the disruption of MBs serves to deposit MNPs into the cytosol directly, in contrast to the co-administration method in which a proportion of MNPs fail to obtain enough energy to enter the cells.

\section{Levels of ROS formation in cells with different uptake pathways}

The capacity of MNPs to generate ROS in HepG2 cells at various times $(0.5,2,6,12$, and $24 \mathrm{~h})$ by different treatment methods was measured. Hydrogen peroxide $\left(\mathrm{H}_{2} \mathrm{O}_{2}\right.$, $500 \mu \mathrm{M}$ )-treated cells were used as positive control in all of the experiments. Fig. 4 shows the median 2,7-dichlorofluorescein (DCF) fluorescence intensity per viable cell in the MNPs-Cell, MNPs-MBs-US-Cells, and MNPs@MBs-USCells samples. Higher DCF fluorescence indicates higher intracellular ROS level. For the short-term treatment intervals $(0.5,2$, and $6 \mathrm{~h})$, the incubation approach results in a slight increase of the ROS formation in the cells. However, both the ultrasound and microbubble groups (MNPs-MBsUS-Cells and MNPs@MBs-US-Cells) show a decrease of the ROS. Surprisingly, for the ultrasound and microbubbles group at 12 and $24 \mathrm{~h}$, the ROS amounts in the cells are somewhat lower $(p<0.05)$ than those by incubation. After $24 \mathrm{~h}$, the intracellular ROS concentration significantly increases for the incubation group (Fig. 4b), whereas there is no significant change for the ultrasound and microbubble treatment groups. These results indicate that ROS formation is totally different for the three groups of samples. A significant uptake pathway-dependent change in intracellular ROS was found in HepG2 cells when interacting with MNPs for longer time intervals (12 and $24 \mathrm{~h}$ ).

\section{Total antioxidant capacity and intracellular glutathione peroxide activity}

The assessment of the total antioxidant capacity (T-AOC) and the GPx was performed for the control and MNP-treated cells. These measurements provide an indication of overall ability to eliminate ROS and resist oxidative damage, despite the fact that no significant differences in T-AOC were detected between the incubation and the control groups after $24 \mathrm{~h}$ treatment (Fig. 5b). A significant increase in T-AOC was observed in the ultrasound and microbubble groups. Interestingly, when the MNPs were delivered into the cells by the microbubbles and ultrasound, the cells showed a higher total antioxidation capability.

The activities of GPx were also assessed in cells treated with different MNP uptake pathways after $24 \mathrm{~h}$ (Fig. 5a). When MNPs were directly incubated with the cells, there was no significant change in GPx activity as compared to the control groups. However, a significant increase in GPx activity is confirmed in both the MNPs-MBs-US-Cells and MNPs@MBs-US-Cell groups, which implies that different internalization routes induce different antioxidation re- 

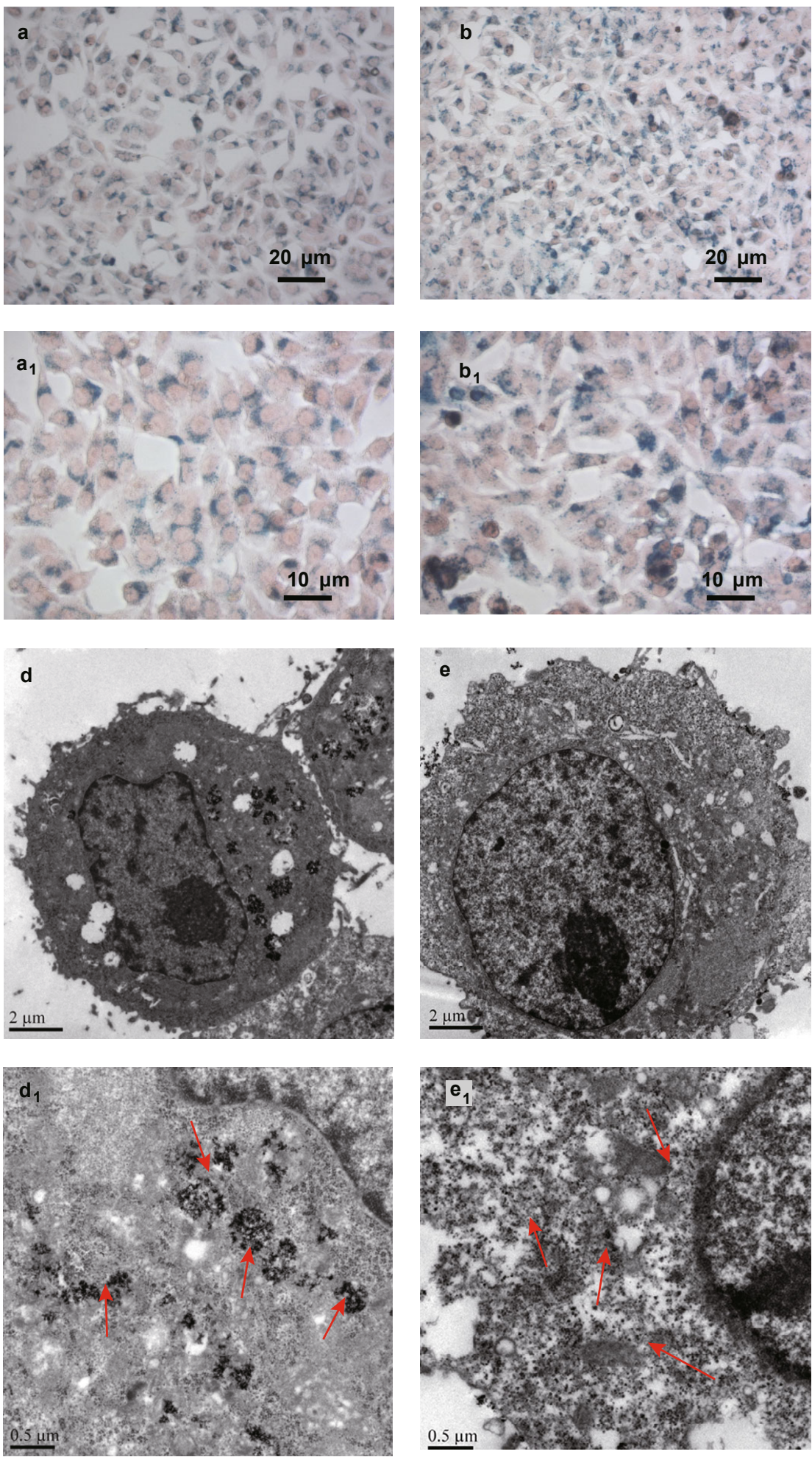
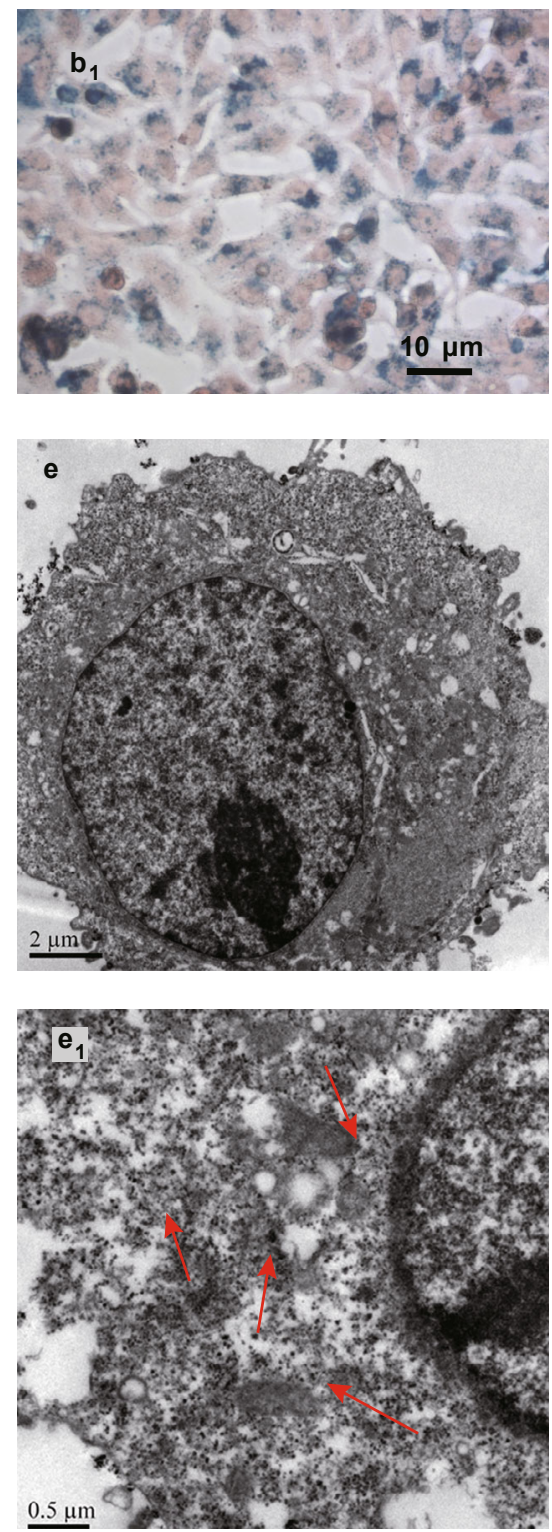
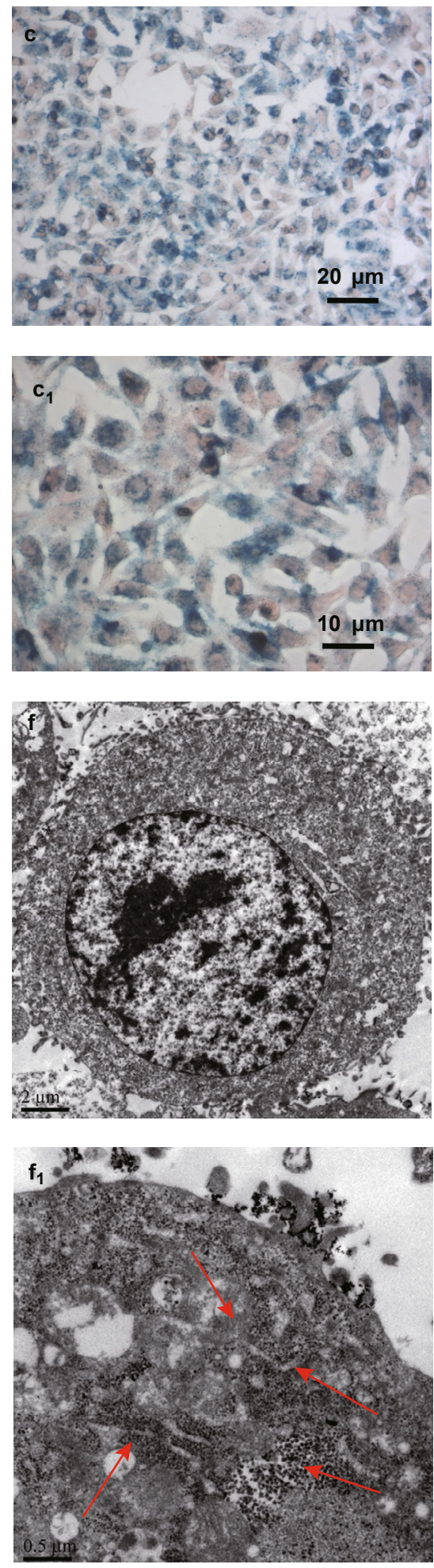

Figure 3 Microscopy and TEM images of $\gamma-\mathrm{Fe}_{2} \mathrm{O}_{3}$ nanoparticle distribution in the cells using different intracellular pathways. (a, d) Cell incubation with nanoparticles for $12 \mathrm{~h}$. (b, e) Cells treated with microbubbles and free MNPs for $40 \mathrm{~s}$ ultrasound exposure. (c, f) Cells treated with MNP-coated microbubbles for $40 \mathrm{~s}$ ultrasound exposure. The images labeled $\left(a_{1}\right),\left(b_{1}\right),\left(c_{1}\right),\left(d_{1}\right),\left(e_{1}\right)$, and $\left(f_{1}\right)$ are the corresponding enlarged images. The results show that different uptake routes result in different nanoparticle localization and distribution within the cells. 

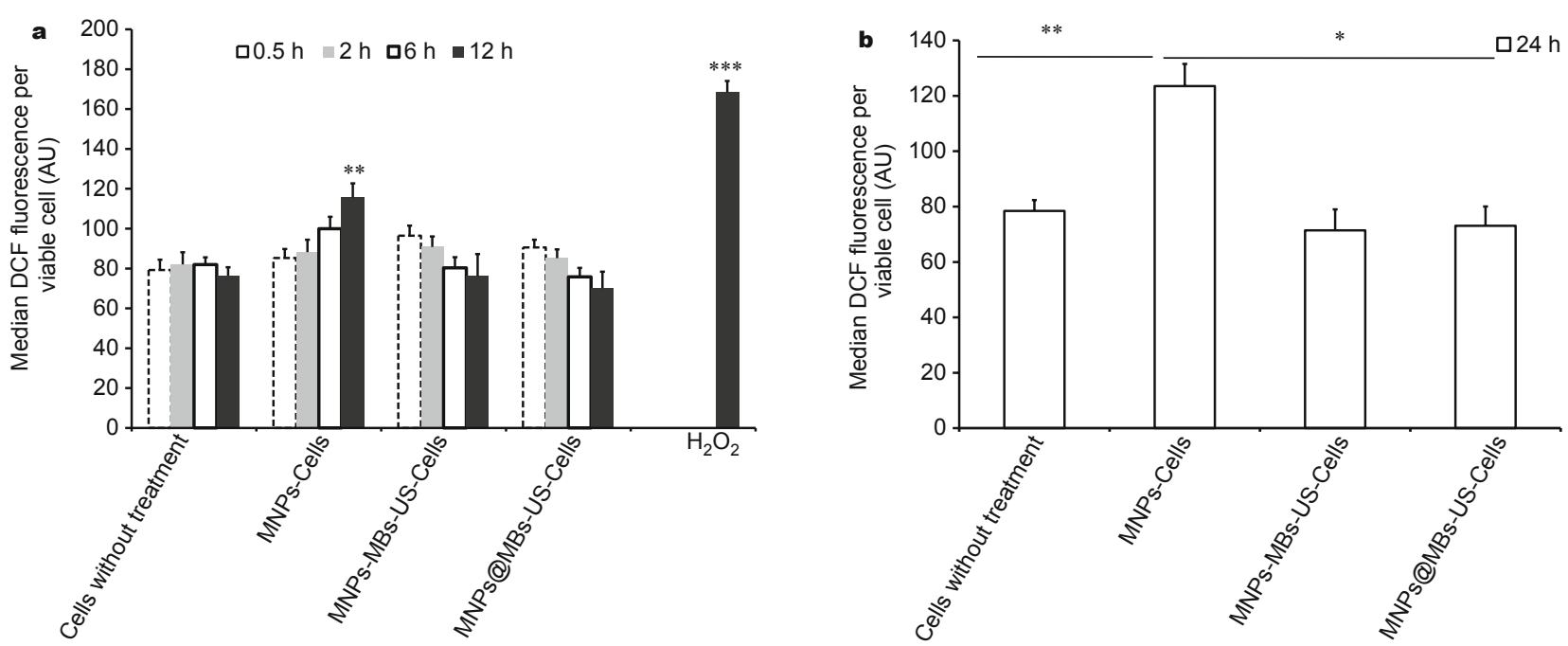

Figure 4 The intracellular ROS level produced by MNP uptake per living cell in HepG2 cells treated with different uptake pathways after (a) 0.5 , 2, 6 , and $12 \mathrm{~h}$ and (b) $24 \mathrm{~h}$. Hydrogen peroxide $(500 \mu \mathrm{M}, 10 \mathrm{~min}$ ) was used as a positive control in these experiments. The columns represent the mean \pm standard deviation (SD) from at least three independent experiments. Significant differences were found with respect to the control group at $* p<0.05$ and $* * p<0.01$.
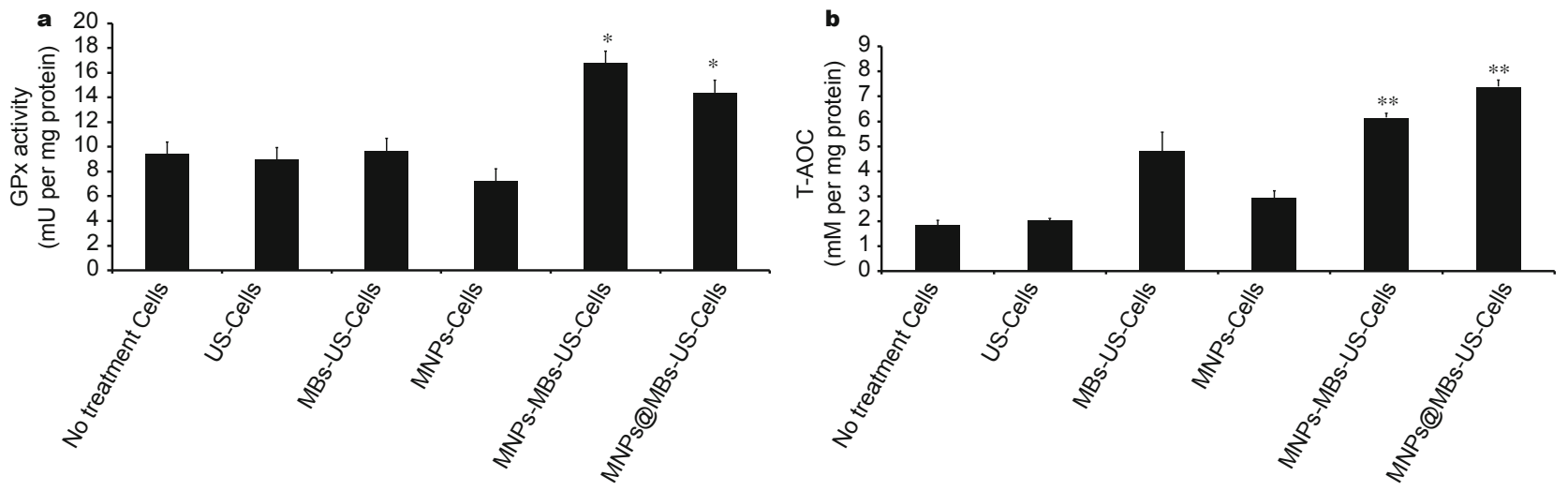

Figure 5 (a) The activity of GPx in HepG2 cells and (b) T-AOC of HepG2 cells treated with different MNP uptake pathways after $24 \mathrm{~h}$. The columns represent the mean $\pm \mathrm{SD}$ from at least three independent experiments per sample. Significant differences with respect to the control group were found at $* \mathrm{p}<0.05$ and $* * \mathrm{p}<0.01$. Results are expressed as mU GPx per mg proteins for GPx activity and as mM trolox-equivalent antioxidant capacity per mg protein.

sponses.

\section{Intracellular lysosome trafficking}

Lysosomal degradation of intracellular MNPs has been proposed to be a major reason for ROS cytotoxicity. Intracellular lysosome conditions can be monitored under fluorescence microscopy by using Lyso-Tracker staining (red fluorescence). As shown in Fig. 6b, the red color for the incubation group is brighter than that for the microbubble and ultrasound groups after $24 \mathrm{~h}$. These results indicate that by incubation, once MNPs enter into the cell, most of them would be captured by lysosome response. However, by using microbubbles and ultrasound methods, it seems that the MNPs escape in significant quantities from the lysosomal membrane and enter the cytoplasm. The quantitative results from flow cytometry also demonstrate that the red fluorescence intensity is higher in the incubation cell group (Fig. 6e).

\section{DISCUSSION}

Magnetic nanoparticles are increasingly used in bioimaging, diagnostic technology, and drug/gene delivery [37]. A 

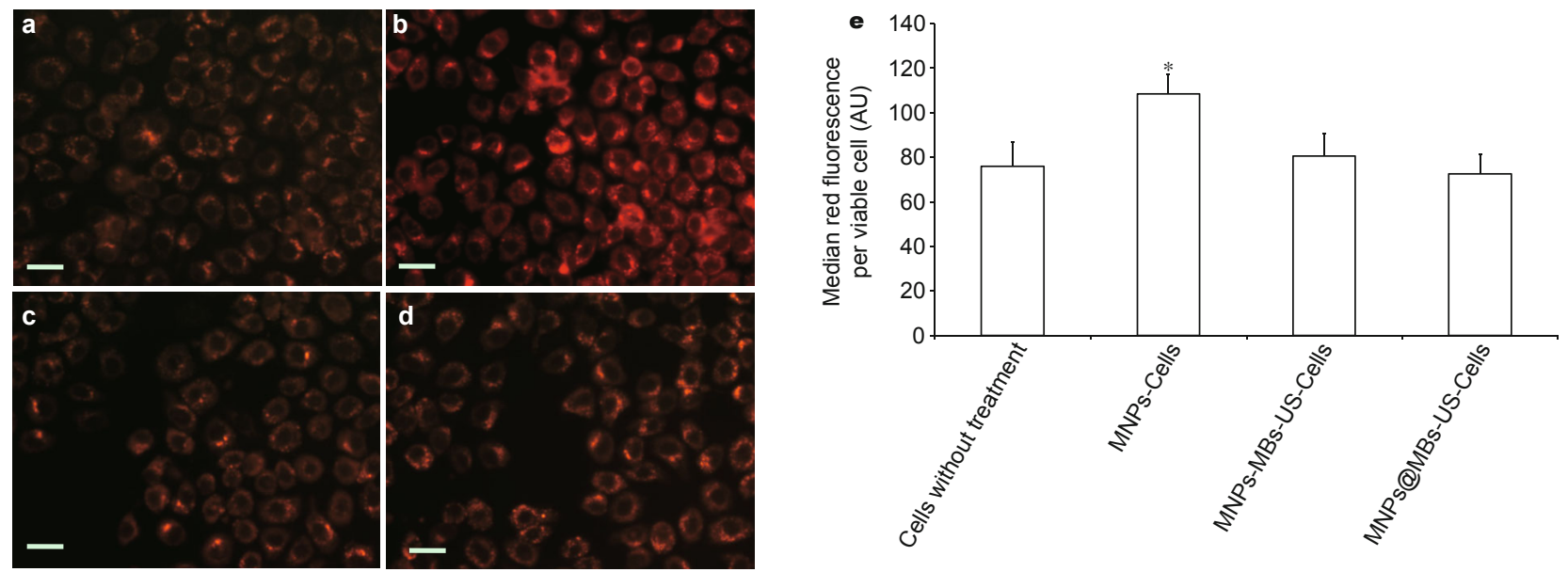

Figure 6 Microscopy images of HepG2 cells after 24 h treated with MNPs using different delivery routes: (a) cells without any treatment, (b) cell incubation with MNPs, (c) MNPs delivered into the cells with the aid of microbubbles and ultrasound, and (d) MNPs loaded on the surface of microbubbles then delivered into the cells by ultrasound exposure. The lysosomes were stained with Lyso-Tracker Red. (e) The median intracellular red fluorescence intensity as a function of the particular MNP uptake pathway per living cell in HepG2 cells treated after $24 \mathrm{~h}$. The columns represent the mean \pm SD from at least three independent experiments per sample. Significant differences with respect to the control group were found at $* \mathrm{p}<0.05$. The scale bar is $10 \mu \mathrm{m}$.

prerequisite for human use of MNPs is a specific efficient transfection and an acceptably low toxicity [38]. The exact mechanism of the biotoxicity of nanosized iron oxides is an ongoing discussion; the most likely causes include size, concentration, and chemical surface modification, as well as incubation time [39]. Voinov et al. [40] reported that $\gamma-\mathrm{Fe}_{2} \mathrm{O}_{3}$ nanoparticles $20-40 \mathrm{~nm}$ in diameter could mediate the production of highly reactive hydroxyl radicals because an increase in the intracellular free iron level affected the normal ROS-antioxidant balance by promoting ROS production. Some studies have speculated that iron oxide nanoparticles could release $\mathrm{Fe}^{2+}$ ions into the cell compartment, thus elevating the intracellular iron concentration when the nanoparticles are endocytized and, consequently, causing oxidative damage through the ROS mechanism $[41,42]$. Thus, it may be promising to design MNP localization strategy to avoid the degradation of the nanoparticles.

Ultrasound-mediated implosion of $\mathrm{MBs}$ may give nanoparticles access to the cell's cytoplasm via short-lived membrane perforations by precisely adjusting the ultrasound parameters. In this study, APTS-modified $\gamma-\mathrm{Fe}_{2} \mathrm{O}_{3}$ was used to study the different delivery approaches to HepG2 tumor cells. Three types of MNP cellular uptake routes were designed: incubation, ultrasound-mediated delivery with a mixture of microbubbles and free MNPs, and an ultrasound-mediated delivery with MNP-loaded microbubbles. As compared with the MNPs-Cells group, MNP delivery efficiency increases by $14.90 \%$ in the MNPs-MBsUS-Cells group and by $23.87 \%$ in the MNPs@MBs-US-
Cells group (Table S1). There is no significant difference between the MNPs-MBs-US-Cells and MNPs@MBs-USCells groups. Treated by microbubbles and ultrasound approaches, more MNPs can be exclusively delivered into the cells, which is beneficial for the enhancement of MNP imaging or drug delivery therapy. For microbubbles with unbound MNPs, only MNPs close to both microbubbles and cell membranes can be delivered into cells. For MNP-decorated microbubbles, the MNPs can enter the cells when the microbubbles are close enough to the cells to cause a disruption.

The TEM and Prussian blue dying images shown in Fig. 3 indicate a different distribution status of MNPs in the intracellular microenvironment. It is obvious that the incubation method leads to the aggregation of MNPs in the cytoplasm. For ultrasound treatment, the MNPs can be uniformly distributed in the cytoplasm. The microscopy images from Lyso-Tracker Red after incubation with $\gamma-\mathrm{Fe}_{2} \mathrm{O}_{3}$ for $24 \mathrm{~h}$ show a strong red fluorescence (Fig. 6b), indicating that an endocytic carrier vesicle filled with MNPs is transported into the cytoplasm along the endosomal pathway toward the lysosomes. In the cytosol, the MNPs accumulated around the membranes of lysosomes, wherein their degradation will take place because of the acidic lysomic microenvironment. For ultrasound and microbubble treatment groups, although there is no significant difference between these two groups, the weaker red fluorescence (Figs $6 \mathrm{c}$ and d) and uniform MNP distribution within the cells (Figs $3 b, c$, e and $\mathrm{f}$ ) indicate that the 
ultrasound exposure forces the MNPs to escape lysosome capture and go directly into the cytoplasm through transit-pore formation on the cell membrane. The pores on the cell membrane were observed by atomic force microscopy (AFM) (Fig. S1). From this point of view, the conventional incubation endocytic pathway and ultrasound treatment approach indeed can induce different intracellular distributions and local perturbation of intracellular processes.

In a normal cellular biochemical cycle, the ROS are continuously produced and effectively neutralized by available antioxidants such as glutathione and by specific enzymes [43]. In our experiments, results indicate that as compared to the incubation method, the delivery of nanoparticles using the ultrasound and microbubble methods can lead to altered oxidative stress outcomes. In terms of the intracellular ROS level, the activity of GPx, and T-AOC of HepG2 cells treated with only microbubbles, only ultrasound and phosphate buffered saline did not show any significant change (Fig. S2). After $24 \mathrm{~h}$, the intracellular ROS concentration significantly increased for the incubation group. The intracellular ROS levels for the microbubble and ultrasound treatment groups are quite stable. The results in our study suggest that (i) the cytotoxicity of MNPs for HepG2 cells becomes significant over time and (ii) ROS production, GSH depletion, and total antioxidant capacity increase could jointly induce the cytotoxicity of MNPs.

It is widely known that the Fenton process involves the generation of hydroxyl radicals $(\cdot \mathrm{OH})$ as the major oxidizing species and $\cdot \mathrm{HO}_{2}$ as the minor oxidizing species, which may be described by Reactions (1), (2) and (3) as follows:

$$
\begin{gathered}
\mathrm{Fe}^{2+}+\mathrm{H}_{2} \mathrm{O}_{2} \rightarrow \mathrm{Fe}^{3+}+\mathrm{OH}^{-}+\cdot \mathrm{OH}, \\
\mathrm{Fe}^{3+}+\mathrm{H}_{2} \mathrm{O}_{2} \rightarrow \mathrm{FeOOH}^{2+}+\mathrm{H}^{+}, \\
\mathrm{FeOOH}^{2+} \rightarrow \mathrm{Fe}^{2+}+\cdot \mathrm{HO}_{2} .
\end{gathered}
$$

Normally, the Fenton process requires $\mathrm{pH}<4$. Iron ions are released into the cytosol because lysosomal enzymatic degradation participates in the Fenton reaction, producing hydroxyl radicals. Therefore, if the MNPs are delivered into the lysosome compartment under acidic lysosomic conditions because of the intrinsic peroxidase-like activity of MNPs, the MNPs can catalyze $\mathrm{H}_{2} \mathrm{O}_{2}$ to produce hydroxyl radicals $[44,45]$. Because of the Fenton reaction, the incubation internalization pathway with the agglomerate of MNPs in the lysosomes can lead to higher ROS production. Hydoxyl radicals generated can indirectly induce cytotoxicity, which results in lower cell viability (Fig. S3). However, by using the ultrasound and microbubble approaches, the MNPs are evenly distributed in the cytoplasm without lysosome capture. In a neutral cytoplasm microenvironment, the reaction rate of Reaction (2) may be higher, and thus excessive $\mathrm{FeOOH}{ }^{2+}$ and $\cdot \mathrm{HO}_{2}$ would be produced. The $\cdot \mathrm{HO}_{2}$ radical can then react with $\mathrm{Fe}^{3+}$ to produce oxygen according to Reaction (4):

$$
\cdot \mathrm{HO}_{2}+\mathrm{Fe}^{3+} \rightarrow \mathrm{Fe}^{2+}+\mathrm{O}_{2}+\mathrm{H}^{+} .
$$

The final product from the Fenton reaction would be oxygen rather than hydroxyl radicals. Thus, no more ROS would be produced through this reaction pathway. Under this condition, although more MNPs are delivered into the cell, the balance of the ROS cycle can be stabilized. In fact, some studies have already reported that both $\mathrm{Fe}_{3} \mathrm{O}_{4}$ and $\gamma-\mathrm{Fe}_{2} \mathrm{O}_{3}$ nanoparticles have dual enzyme-like activities, which means both intrinsic peroxidase-like activity in an acidic solution and a catalase-like activity at neutral $\mathrm{pH}$ (pH 7.4) [46,47]. Fan et al. [48] reported that MNPs could catalyze $\mathrm{H}_{2} \mathrm{O}_{2}$ to produce hydroxyl radicals in acidic lysosome-mimic conditions, but no hydroxyl radicals were observed in neutral cytosol-mimic conditions. Therefore, the ROS toxicity of MNPs may be uptake-route-dependent. In order to decrease the MNP ROS toxicity when endocytized by cells during the incubation process, it is ideal to manipulate the MNPs to enter specific intracellular compartments. A schematic of the three types of uptake pathways is shown in Fig. 7, which indicates that incubation and sonoporation can induce different ROS responses because MNPs can be distributed in different intracellular microenvironments.

All in all, although it is not yet clear whether the lower cytotoxicity from the ultrasound group is one of the results of transient sonoporation, our data suggest that higher transfection efficiency and reduced toxicity can be tuned to achieve nanoparticle delivery by using the microbubble-mediated ultrasound treatment approach. The reduction of toxicity may result from different ROS production based on different MNP delivery pathways. Further studies are required in order to thoroughly investigate the different ROS responses between free MNPs and MNP-decorated microbubbles.

\section{CONCLUSION}

In summary, cellular uptake, intracellular trafficking, and cytotoxicity are important steps towards understanding the biologically adverse or favorable functions of nanoparticles in biomedical applications. In this study, different cellular ROS responses were investigated under different uptake pathways using $12 \mathrm{~nm} \gamma-\mathrm{Fe}_{2} \mathrm{O}_{3}$ interactions with cells at a concentration of $20 \mu \mathrm{g}$. The ultrasound-responsive microbubble carriers not only promote magnetic nanoparticles intracellular uptake efficiency but also deliver nanoparticles into the cytosol by the formation of pores on the cell membrane. As compared to the conventional incubation 


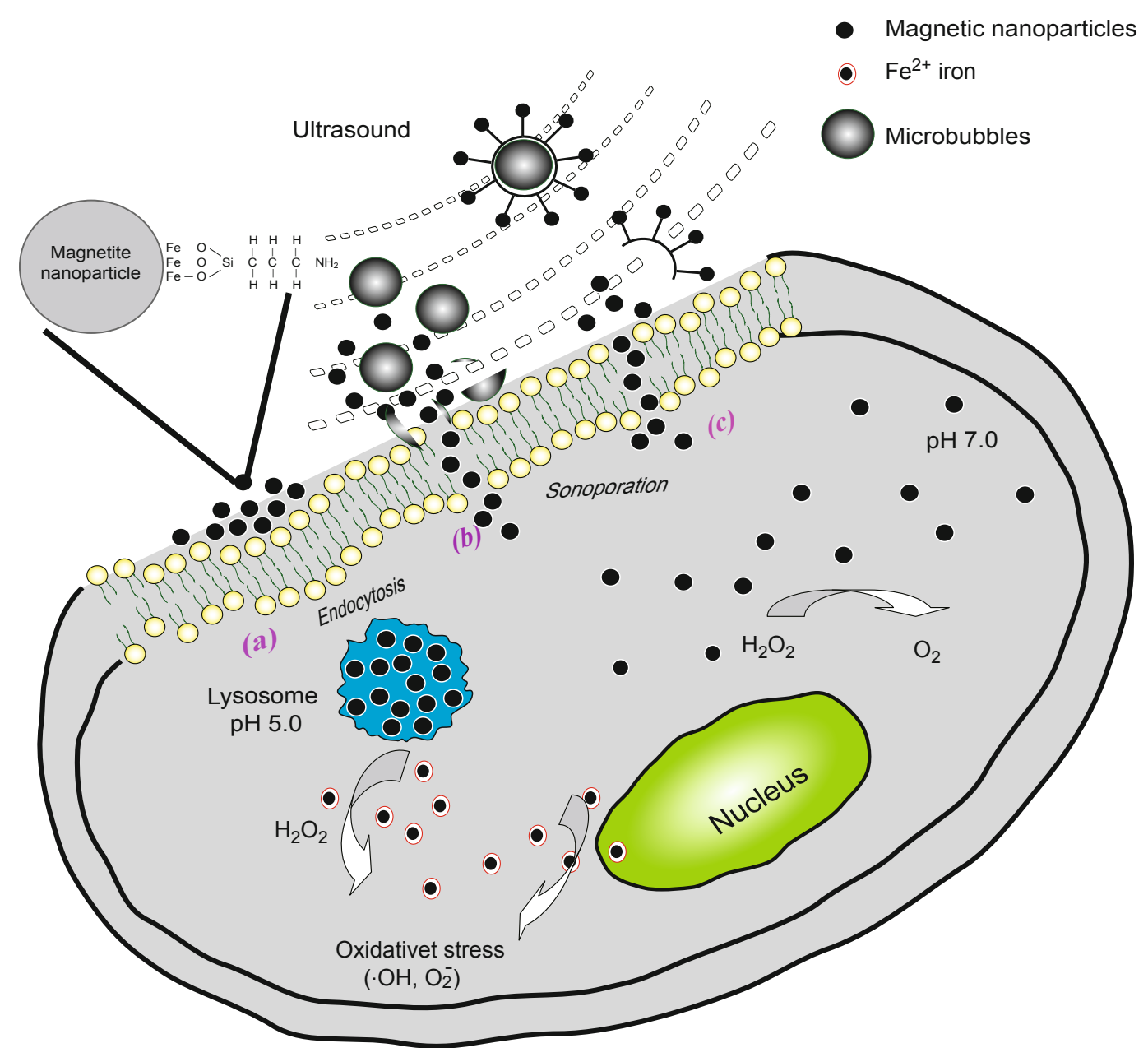

Figure 7 Schematic of different intracellular uptake pathways of MNPs: (a) incubation of MNPs with cells, which displays internalization and aggregation in lysosomes. (b) and (c) Sonoporation induced by ultrasound and microbubbles with unbound and bound nanoparticles, respectively, results in the MNPs accessing the cytosol of cells. The uniform distribution and neutral cytosolic microenvironment would decompose $\mathrm{H}_{2} \mathrm{O}_{2}$ into oxygen through catalase-like activity, which would avoid the long-term cytotoxicity in the intracellular therapy and imaging applications.

approaches, the microbubble-mediated ultrasound pathway offers the cells higher GPx and total antioxidant capacity, which further prevents intracellular ROS generation. Therefore, the microbubble-mediated ultrasound MNP delivery strategy could not only significantly enhance delivery efficiency, it could also reduce bio-effect concerns and their potential long-term toxicity.

\section{EXPERIMENTAL SECTION}

\section{Materials}

Aminopropyltriethoxysilane (APTS)-modified superparamagnetic iron oxide nanoparticles of $\gamma$ - $\mathrm{Fe}_{2} \mathrm{O}_{3}$ (ATPS@ $\gamma-\mathrm{Fe}_{2} \mathrm{O}_{3}$ ) were provided by Jiangsu Key Laboratory for Biomaterials and Devices. Poly (vinyl alcohol) (PVA) $\left(M_{\mathrm{w}}=31,000\right)$ was from Sigma-Aldrich (St. Louis, MO,
USA); poly (L-lactide) (PLLA) $\left(M_{\mathrm{w}}=30,000\right)$ was from Shandong Daigang Company (China). Sodium periodate and sodium chlorite were purchased from Shantou Xilong Chemical Company (China). 1-Ethyl-3-(3-dimethylaminopropyl) carbodiimide (EDC) and 2-( $N$-morpholino) ethanesulfonic acid (MES) were from Shanghai Medpep Company (China). Lyso-Tracker-Red, an oxidation-sensitive fluorescent probe (DCFH-DA), a T-AOC assay kit, and a total glutathione assay kit were purchased from the Beyotime Institute of Biotechnology (Haimen, Jiangsu, China). 3-(4,5-Dimethylthiazol-2-yl)-2,5-diphenyl tetrazolium bromide (MTT) and glutaraldehyde were purchased from Sigma Aldrich. Culture media, fetal bovine serum (FBS), antibiotics, and other chemicals used for cell cultivation were purchased from Gibco (KeyGEN Biotech. Co., Ltd., Nanjing, China). All other chemicals and solvents were of 
analytical grade.

\section{Fabrication and characterization of microbubbles}

The MNP-coated microbubbles were prepared as previously described [49]. Briefly, the telechelic PVA-encapsulated microcapsules were prepared by multi-emulsion methods and then suspended in MES buffer ( $50 \mathrm{mM}, \mathrm{pH}$ 5.4). The suspension was activated by $\mathrm{EDC}\left(0.4 \mathrm{mg} \mathrm{mL}^{-1}\right)$ at room temperature and then incubated with a certain amount of ATPS-coated $\gamma-\mathrm{Fe}_{2} \mathrm{O}_{3}$ nanoparticles. After $8 \mathrm{~h}$, the products were collected and washed three times by MES buffer (50 mM, pH 5.4). Microbubbles without nanoparticles were synthesized using the same method without adding MNPs. The final samples were stored as lyophilisates (FreeZone freeze dryer, Labconco, USA) using mannitol as a protective agent. Before all experiments, the microbubbles were directly resuspended in phosphate-buffered saline (PBS). The iron concentration in the aqueous dispersion of the MBs was determined by the 1,10-phenanthroline colorimetric method. Size distribution analysis of both microbubbles with unbound and bound nanoparticles was performed. For measuring the ultrasonic backscattering properties of microbubbles, an ultrasonic probe with an average frequency of $2.25 \mathrm{MHz}$, a bandwidth of $40 \%$, and a pulse repetition frequency (PRF) of $3 \mathrm{kHz}$ was used. The $\mathrm{RF}$ signal before logarithmic amplification and envelope extraction was acquired using a digital oscilloscope (UniTrend Group Limited, Shenzhen, China).

\section{Cell culture}

HepG2 (Hepatocellular carcinoma, human) was purchased from the Institute of Biochemistry and Cell Biology, Shanghai Institute of Biological Sciences, Chinese Academy of Sciences (China). Cells were cultured in an RPMI 1640 medium containing $10 \%$ fetal calf serum (FCS), penicillin $\left(100 \mu \mathrm{g} \mathrm{mL}^{-1}\right)$, and streptomycin $\left(100 \mu \mathrm{g} \mathrm{mL}^{-1}\right)$. The cells were incubated at $37^{\circ} \mathrm{C}$ in $5 \% \mathrm{CO}_{2}$ atmosphere and the medium was replaced every other day.

\section{Administration of nanoparticles into cells}

Three administration methods were employed for MNP delivery into the HepG2 cells. The first was incubation of the MNPs with the cells. The second was co-administration of free MNPs and microbubbles with the cells under ultrasound exposure. The third was treating the cells with MNP-decorated microbubbles by ultrasound. The corresponding samples are denoted as MNPs-Cell, MNPs-MBsUS-Cells, and MNPs@MBs-US-Cells, respectively.

For incubation, $1 \times 10^{6}$ cells per well were placed in 6-well plates and settled overnight for adherence. Then, the purified ATPS-modified $\gamma$ - $\mathrm{Fe}_{2} \mathrm{O}_{3}$ nanoparticles were added into the wells to obtain a final concentration of $20 \mu \mathrm{g}$ MNPs. After 0.5, 2, 6, 12, and $24 \mathrm{~h}$ incubation, cells were collected for the following measurements.

For the ultrasound exposure experiments, exponentially growing cells were harvested and resuspended in fresh PBS. The concentration of the cells was diluted to $1 \times 10^{6}$ cells $\mathrm{mL}^{-1}$. The concentration ratio of microbubbles to cells was approximately 1:10. After the MBs were mixed well with the cells, ultrasound was applied. An ultrasound transducer $(1 \mathrm{MHz}$, diameter $30 \mathrm{~mm}$ ) was driven by a function generator (33250A, Agilent Technologies, USA) and a power amplifier (75A250, Amplifier Research, USA), with its active surface submerged in the water tank $8 \mathrm{~cm}$ from the sample tube. The transducer was calibrated in a free field in water using a calibrated $40-\mu \mathrm{m}$-needle hydrophone (HPM04/1, Precision Acoustics, USA). The acoustic pressure used in this study was $0.25 \mathrm{MPa}$, and the sinewave ultrasound tone bursts comprised 20 cycles per tone burst at a pulse repetition frequency (PRF) of $10 \mathrm{kHz}$. After ultrasound exposure and centrifugation isolation to separate the redundant MNPs and microbubbles, the cells were placed in 6-well plates. After 0.5, 2, 6, 1, 2 and 24 h culture, cells were collected for further analysis.

\section{Cellular viability and nanoparticle delivery efficiency within cells}

After interaction with the MNPs, the cell viability was determined by the assay of tetrazolium salt MTT. An assay medium containing MTT $\left(5 \mathrm{mg} \mathrm{mL}^{-1}, 20 \mu \mathrm{L}\right)$ was added to each well and incubated at $37^{\circ} \mathrm{C}$ for $4 \mathrm{~h}$. The medium was gently removed, and then dimethylsulphoxide (DMSO, $150 \mu \mathrm{L}$ ) was added to each well to solubilize the formazan crystals. The cells were quantified by measuring the absorbance of the solution by a microplate reader (Model 680, Bio-RAD, USA) at $570 \mathrm{~nm}$.

In order to measure the iron concentration within the cells, the final cell sample was treated in $30 \% \mathrm{HCl}(\mathrm{v} / \mathrm{v})$ at $60^{\circ} \mathrm{C}$. The $10 \%$ hydroxylamine chloride $(0.5 \mathrm{~mL})$ was then added to deoxidize the ferric ions present in the above solution to ferrous ions. $0.1 \%$ phenanthrene solution $(1 \mathrm{~mL})$, sodium acetate buffer, and water were added to the final volume $(2.5 \mathrm{~mL})$. The complex mixture was read after 10 min at $510 \mathrm{~nm}$ using a UV-vis spectrophotometer. A standard curve for the iron was made under identical conditions using a series of $\mathrm{NH}_{4} \mathrm{Fe}\left(\mathrm{SO}_{4}\right)_{2}$ solutions with known concentrations.

\section{Intracellular distribution of magnetic nanoparticles}

For Prussian blue staining, cells were fixed with $4 \%$ glutar- 
aldehyde, washed, incubated for $30 \mathrm{~min}$ with $2 \%$ potassium ferrocyanide in $6 \% \mathrm{HCl}$, washed, and counterstained with nuclear fast red. Then the optical images were obtained by using the bright field of a microscope equipped with a digital Coolsnap MP3.3 camera (Axioskop 200, Carl Zeiss, Germany).

For further understanding the distribution of MNPs in cells, transmission electron microscopy (TEM) observation was used. Cell samples were detached and fixed overnight with $2.5 \%$ glutaraldehyde in PBS $(0.01 \mathrm{M})$ at $4^{\circ} \mathrm{C}$. The samples were then post-fixed in $1 \%$ osmium tetroxide, dehydrated in ethanol, and embedded in Epon. The ultrathin sections $(60-80 \mathrm{~nm})$ were stained with uranyl acetate and lead citrate and then examined with a TEM (JEOL/JEM2000E, Japan).

\section{Detection of intracellular reactive oxygen species}

The DCFH-DA assay has been shown to be a useful tool for the quantitative measurement of nanoparticle-induced oxidative stress [50]. The kinetics of HepG2 intracellular ROS generation was determined in the treated group with MNPs-Cell, MNPs-MBs-US-Cells, or MNPs@MBs-USCells at several sampling time intervals $(0.5,2,6,12$, and $24 \mathrm{~h})$. After interaction with MNPs, cells were incubated with an oxidation-sensitive fluorescent probe DCFH-DA $(10 \mu \mathrm{M})$ in serum-free culture medium for $30 \mathrm{~min}$ at $37^{\circ} \mathrm{C}$ according to the manufacturer's instructions. DCFH-DA was deacetylated intracellularly by nonspecific esterase, which was further oxidized by ROS to the fluorescent compound DCF. DCF fluorescence was monitored by a BD FACS Calibur flow cytometer (BD Biosciences, USA) using $480 \mathrm{~nm}$ excitation and $540 \mathrm{~nm}$ emission settings. For each sample, 10,000 events were collected.

\section{Intracellular glutathione peroxidase activity assay}

The GPx activity was measured by using the total cellular glutathione peroxidase assay kit according to the manufacturer's protocol. Cells were treated by $0.02 \%$ EDTA and then collected in PBS. Cells $\left(1 \times 10^{6}\right)$ were then lysed with $20 \mathrm{mM}$ cell lysis buffer. The lysate was then centrifuged at $12,000 \mathrm{rpm}$ at $4^{\circ} \mathrm{C}$ for $10 \mathrm{~min}$, and the supernatant $(20$ $\mu \mathrm{L})$ was assayed. Reactions included sample $(10 \mu \mathrm{L})$, glutathione peroxidase assay working solution $(10 \mu \mathrm{L}$ of 4.8 mM NADPH, $40.4 \mathrm{mM}$ GSH, and a glutathione reductase solution supplied by the manufacturer), cumene hydroperoxide (CumOOH, $4 \mu \mathrm{L}$ of $15 \mathrm{mM}$ ), and glutathione peroxidase assay buffer (up to $200 \mu \mathrm{L}$ ). Three blank (no sample) and three background (no $\mathrm{CumOOH}$ ) controls were performed in the initial assay at $340 \mathrm{~nm}$. Absorbance measurements were obtained at $30 \mathrm{~s}$ intervals for $3 \mathrm{~min}$ per sample.
One unit of glutathione peroxidase activity was defined as the amount required to oxidize $1 \mu \mathrm{mol} \mathrm{NADPH}$ to $\mathrm{NADP}^{+}$ in $1 \mathrm{~min}$ at $25^{\circ} \mathrm{C}, \mathrm{pH} 8.0$.

\section{Total antioxidant capacity}

The T-AOC was measured using the antioxidant capacity assay kit of 2,2'-azino-bis (3-ethylbenzthiazoline-6-sulfonic acid) (ABTS) according to the manufacturer's recommendations. Briefly, the stock solutions included ABTS solution and an oxidant solution. The working solution was prepared by mixing the two stock solutions in equal quantities and allowing them to react for $16 \mathrm{~h}$ at room temperature in the dark. The solution was then diluted by mixing the working solution $(1 \mathrm{~mL})$ with $80 \%$ ethanol $(90$ $\mathrm{mL}$ ) in order to obtain an absorbance of $0.7 \pm 0.05$ at 734 $\mathrm{nm}$. A fresh ABTS solution was prepared for each assay. After collecting $1 \times 10^{6}$ cells, cells were washed with PBS and homogenized with PBS $(200 \mu \mathrm{L})$ on ice to totally extract the antioxidant agents from cells. Then, the upper mixture, centrifuged at $12,000 \mathrm{rpm}$ for $5 \mathrm{~min}$, was used to measure the T-AOC. Samples were mixed with fresh ABTS solution $(200 \mu \mathrm{L})$, and the mixture was left at room temperature for $6 \mathrm{~min}$. The absorbance was then measured at $734 \mathrm{~nm}$. Trolox was used as a reference compound. The T-AOC for samples can be defined as trolox-equivalent antioxidant capacity (TEAC). Based on the total protein in the sample, the T-AOC can be expressed as $\mathrm{mM}$ per g protein.

\section{Intracellular trafficking of lysosome}

In order to understand whether the lysosomes play a role in the different nanoparticle uptake pathways, at specific time points during post treatment, the cells were rinsed and incubated in a medium containing Lyso-Tracker Red for $1 \mathrm{~h}$. The cells were fixed with fresh $4 \%$ paraformaldehyde and then treated with hoechest $33245\left(10 \mathrm{mg} \mathrm{mL}^{-1}\right)$ in PBS for $10 \mathrm{~min}$. The microscopy images were taken by using the epifluorescent mode (excitation wavelength: $488 \mathrm{~nm}$; fluorescence wavelength: $530 \mathrm{~nm}$ ) of a microscope equipped with a digital Coolsnap MP3.3 camera (Axioskop 200, Carl Zeiss, Germany), and the median fluorescence intensity of lysosome in red was obtained by using a BD FACS Calibur flow cytometer (BD Biosciences, USA).

\section{Statistical analysis}

The measurements for each treatment were repeated in three separate wells with similar cell counts, and the results are presented as mean values $\pm \mathrm{SD}$. The differences between the control cells and treated cells were evaluated by Student's t-test and one-way analysis of variance. Statistical significance was accepted when the probability of the result 
assuming the null hypothesis $(p)$ was less than 0.05 .

Received 9 May 2015; accepted 5 June 2015; published online 19 June 2015

1 Janib SM, Moses A, MacKay JAS. Imaging and drug delivery using theranostic nanoparticles. Adv Drug Deliver Rev, 2010, 61: 10521063

2 Shi D, Bedford NM, Cho HS. Engineered multifunctional nanocarriers for cancer diagnosis and therapeutics. Small, 2011, 7: 25492567

3 Gupta AK, Gupta M. Synthesis and surface engineering of iron oxide nanoparticles for biomedical applications. Biomaterials, 2005, 26: $3995-4021$

4 Gupta AK, Naregalkar RR, Vaidya VD, Gupta M. Recent advances on surface engineering of magnetic iron oxide nanoparticles and their biomedical applications. Nanomedicine-UK, 2007, 2: 23-39

5 Kumar CSSR, Mohammad F. Magnetic nanomaterials for hyperthermia-based therapy and controlled drug delivery. Adv Drug Deliver Rev, 2011, 63: 789-808

6 Lee J, Kim J, Cheon J. Magnetic nanoparticles for multi-imaging and drug delivery. Mol Cells, 2013, 35: 274-284

7 Felton C, Karmakar A, Gartia Y, et al. Magnetic nanoparticles as contrast agents in biomedical imaging: recent advances in iron- and manganese-based magnetic nanoparticles. Drug Metab Rev, 2014, 46: $142-154$

8 Lee JH, Huh YM, Jun YW, et al. Artificially engineered magnetic nanoparticles for ultra-sensitive molecular imaging. Nat Med, 2006, 13: 95-99

9 Jain TK, Morales MA, Sahoo SK, et al. Iron oxide nanoparticles for sustained delivery of anticancer agents. Mol Pharm, 2005, 2: 194-205

10 Reddy LH, Arias JL, Nicolas J, Couvreur P. Magnetic nanoparticles: design and characterization, toxicity and biocompatibility, pharmaceutical and biomedical applications. Chem Rev, 2012, 112 5818-5878

11 Howar M, Zern BJ, Anselmo AC, et al. Vascular targeting of nanocarriers: perplexing aspects of the seemingly straightforward paradigm. ACS Nano, 2014, 8: 4100-4132

12 Liu Y, Chen Z, Wang J. Systematic evaluation of biocompatibility of magnetic $\mathrm{Fe}_{3} \mathrm{O}_{4}$ nanoparticles with six different mammalian cell lines. J Nanopart Res, 2011, 13: 199-212

13 Ferrari M. Cancer nanotechnology: opportunities and challenges. Nature, 2005, 5: 161-171

14 Nel A, Xia T, Mädler L, Li N. Toxic potential of materials at the nanolevel. Science, 2006, 311: 622-627

15 Futerman AH, van Meer G. The cell biology of lysosomal storage disorders. Nat Rev Mol Cell Bio, 2004, 5: 554-565

16 Hillaireau H, Couvreur P. Nanocarriers' entry into the cell: relevance to drug delivery. Cell Mol Life Sci, 2009, 66: 2873-2896

17 Hu Y, Litwin T, Nagaraja AR, et al. Cytosolic delivery of membrane-impermeable molecules in dendritic cells using $\mathrm{pH}$-responsive core-shell nanoparticles. Nano Lett, 2007, 7: 3056-3064

18 Sandhu KK, McIntosh CM, Simard JM, Smith SW, Rotello VM. Gold nanoparticle-mediated transfection of mammalian cells. Bioconjugate Chem, 2002, 13: 3-6

19 Rojas-Chapana JA, Correa-Duarte MA, Ren ZF, Kempa K, Giersig M. Enhanced introduction of gold nanoparticles into vital Acidothiobacillus ferrooxidans by carbon nanotube-based microwave electroporation. Nano Lett, 2004, 4: 985-988

20 Alkins R, Burgess A, Ganguly M, et al. Focused ultrasound delivers targeted immune cells to metastatic brain tumors. Cancer Res, 2013, 73: 1892-1899
21 Geers B, Wever OD, Demeester J, Bracke M, Saefaan C. Targeted liposome-loaded microbubbles for cell-specific ultrasound-triggered drug delivery. Small, 2013, 9: 4027-4035

22 Hauff P, Seemann S, Reszka R, et al. Evaluation of gas-filled microparticles and sonoporation as gene delivery system: feasibility study in rodent tumor models. Radiology, 2005, 236: 572-578

23 Prentice P, Cuschieri A, Dholakia K, Prausnitz M, Campbell P. Membrane disruption by optically controlled microbubble cavitation. Nat Phys, 2005, 1: 107-110

24 Lum AFH, Borden MA, Dayton PA, et al. Ultrasound radiation force enables targeted deposition of model drug carriers loaded on microbubbles. J Control Release, 2006, 111: 128-134

25 Marmottant P, Hilgenfeldt S. Controlled vesicle deformation and lysis by single oscillating bubbles. Nature, 2003, 423: 153-156

26 Wu J, Nyborg WL. Ultrasound, cavitation bubbles and their interaction with cells. Adv Drug Deliver Rev, 2008, 60: 1103-1116

27 Fan Z, Liu H, Mayer M, Deng CX. Spatiotemporally controlled single cell sonoporation. Proc Natl Acad Sci USA, 2012, 109: 1648616491

28 Hussain SM, Hess KL, Gearhart JM, Geiss KT, Schlager JJ. In vitro toxicity of nanoparticles in BRL 3A rat liver cells. Toxicol In Vitro, 2005, 19: 975-983

29 Elsaesser A, Howard CV. Toxicology of nanoparticles. Adv Drug Deliver Rev, 2012, 64: 129-137

30 Pivtoraiko VN, Stone SL, Roth KA, Shacka JJ. Oxidative stress and autophagy in the regulation of lysosome-dependent neuron death antioxid. Redox Sign, 2009, 11: 481-496

31 Li JJ, Hartono D, Ong CN, et al. Autophagy and oxidative stress associated with gold nanoparticles. Biomaterials, 2010, 31: 5996-6003

32 Mesárǒsová $\mathrm{M}$, Kozicsa $\mathrm{K}$, Bábelováa $\mathrm{A}$, et al. The role of reactive oxygen species in the genotoxicity of surface-modified magnetite nanoparticles. Toxicol Lett, 2014, 226: 303-313

33 Klein S, Sommer A, Distel LVR, Neuhuber W, Kryschi C. Superparamagnetic iron oxide nanoparticles as radiosensitizer via enhanced reactive oxygen species formation. Biochem Biophys Res Commun, 2012, 425: 393-397

34 Soenen SJH, Himmelreich U, Nuytten N, De Cuyper M. Cytotoxic effects of iron oxide nanoparticles and implications for safety in cell labelling. Biomaterials, 2011, 32: 195-205

35 Mullin LB, Philips LC, Dayton PA. Nanoparticle delivery enhancement with acoustically activated microbubbles. IEEE Trans Ultrason Ferroelectr Freq Control, 2013, 60: 65-77

36 Yang F, Zhang M, He W, et al. Controlled release of $\mathrm{Fe}_{3} \mathrm{O}_{4}$ nanoparticles in encapsulated microbubbles to tumor cells via sonoporation and associated cellular bioeffects. Small, 2011, 7: 902-910

37 Shubayev VI, Pisanic TR, Jin SH. Magnetic nanoparticles for theragnostics. Adv Drug Deliv Rev, 2009, 61: 467-477

38 Mesarosova M, Ciampor F, Zavisova V, et al. The intensity of internalization and cytotoxicity of superparamagnetic iron oxide nanoparticles with different surface modifications in human tumor and diploid lung cells. Neoplasma, 2012, 59: 584-597

39 Thorek DLJ, Tsourkas A. Size, charge and concentration dependent uptake of iron oxide particles by non-phagocytic cells. Biomaterials, 2008, 29: 3583-3590

40 Voinov MA, Pagan JOS, Morrison E, Smirnova TI, Smirnov AI. Surface-mediated production of hydroxyl radicals as a mechanism of iron oxide nanoparticle biotoxicity. J Am Chem Soc, 2011, 133: 35-41

41 Gan Q, Lu X, Dong W, et al. Endosomal pH-activatable magnetic nanoparticle-capped mesoporous silica for intracellular controlled release. J Mater Chem, 2012, 22: 15960-15968

42 Sharma G, Kodali V, Gaffrey M. et al. Iron oxide nanoparticle agglomeration influences dose rates and modulates oxidative 
stress-mediated dose-response profiles in vitro. Nanotoxicology, 2014, 8: 663-675

43 Schumacker PT. Reactive oxygen species in cancer cells: live by the sword, die by the sword. Cancer Cell, 2006, 10: 175-176

44 Chen Z, Yin J, Zhou YT, et al. Dual enzyme-like activities of iron oxide nanoparticles and their implication for diminishing cytotoxicity. ACS Nano, 2012, 6: 4001-4012

45 Gao LZ, Zhuang J, Nie L, et al. Intrinsic peroxidase-like activity of ferromagnetic nanoparticles. Nat Nanotechnol, 2007, 2: 577-583

46 Fan J, Lin JJ, Ning B, et al. Direct evidence for catalase and peroxidase activities of ferritin-platinum nanoparticles. Biomaterials, 2011, 32: 1611-1618

47 Bedard K, Krause KH. The NOX family of ROS-generating NADPH oxidases: physiology and pathophysiology. Physiol Rev, 2007, 87: 245-313

48 Pangu GD, Davis KP, Bates FS, Hammer DA. Ultrasonically induced release from nanosized polymer vesicles. Macromol Biosci, 2010, 10: 546-554

49 He W, Yang F, Wu Yihang, et al. Microbubbles with surface coated by superparamagnetic iron oxide nanoparticles. Mater Lett, 2012, 68: 64-67

50 Aranda A, Sequedo L, Tolosa L, et al. Dichloro-dihydro-fluorescein diacetate (DCFH-DA) assay: a quantitative method for oxidative stress assessment of nanoparticle-treated cells. Toxicol In Vitro, 2013, 27: 954-963
Acknowledgements This investigation was financially funded by the project of National Key Basic Research Program of China (2011CB933503 and 2013CB733804), the National Natural Science Foundation of China (NSFC) (31370019 and 61127002), Jiangsu Provincial Special Program of Medical Science (BL2013029). Partial funding also came from the Author of National Excellent Doctoral Dissertation of China (201259), as well as from the Fundamental Research Funds for the Central Universities.

Author contributions Yang F, Zhang Y and Gu N developed the initial concept. Yang F, Li M and Chen Z designed the experiments. Yang F, Li $\mathrm{M}$ and $\mathrm{Cui} \mathrm{H}$ performed the experiments and data analysis. Chen $\mathrm{Z}$ and Wang $\mathrm{T}$ cultured the cells. Song $\mathrm{L}$ and Zhang $\mathrm{Y}$ prepared and characterized the magnetic nanoparticles. Yang F, Li M, Cui H, Gu Z and Gu N cowrote the manuscript. Yang F and Gu N supervised the study. All authors discussed the results and commented on the manuscript.

Conflict of interest The authors declare that they have no conflict of interest.

Supplementary information Supplementary data include the efficiency of magnetic nanoparticles entering into the cells after different cellular uptake pathways; AFM scans of the outer cell membrane after ultrasound exposure with microbubbles; intracellular ROS level, activity of GPx, and T-AOC of HepG2 cells treated with only microbubbles, only ultrasound, and phosphate buffered saline, respectively; cell viability after different cellular uptake pathways. These materials are available free of charge via the online version of this paper 


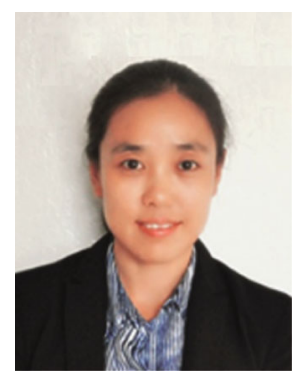

Fang Yang was born in 1979. She received her $\mathrm{PhD}$ degree in biomedical engineering from the School of Biological Science and Medical Engineering, Southeast University, Nanjing, China, in 2009. Currently, she works at the School of Biological Science and Medical Engineering, Southeast University. Her research interests mainly focus on ultrasound multi-modal imaging; ultrasound molecular imaging, and imaging (ultrasound, magnetic resonance, optical, CT, etc.) guided drug delivery system, etc.

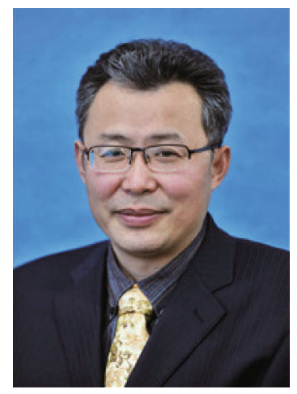

Ning Gu was born in 1964. He received his $\mathrm{PhD}$ degree in biomedical engineering from the Department of Biomedical Engineering, Southeast University, Nanjing, China, in 1996. Currently he is a Changjiang Scholar Professor and NSFC Outstanding Young Investigator Fund Winner at the School of Biological Science and Medical Engineering, Southeast University. He also serves as the president of Jiangsu Society of Biomedical Engineering, the director of the Research Center for Nanoscale Science and Technology of Southeast University. His research interests include biomaterials, nanobiology, medical imaging, advanced instrument development, etc.

中文摘要 磁性纳米颗粒在纳米生物医学诊断和治疗研究领域是极具潜力的一种纳米材料. 如何实现纳米颗粒在特定细胞或靶器官的 高效率传输以及如何降低细胞毒性是目前纳米材料研究的重点内容. 本文首先研究了 $12 \mathrm{~nm}$ 的 $\gamma-\mathrm{Fe}_{2} \mathrm{O}_{3}$ 磁性纳米颗粒进入细胞的三种不 同途径: (1) 纳米颗粒与肿瘤细胞共捊育后的内吞途径; (2) 纳米颗粒与微气泡共混合后超声辐照传输途径; (3) 纳米颗粒化学偶联到微 气泡膜壳表面后超声辐照传输途径. 其次, 基于上述三种不同的纳米颗粒传输途径, 对纳米颗粒引起的细胞氧化应激毒性进行了深入 研究. 结果表明, 纳米颗粒与肿瘤细胞共捊育后的内吞途径使纳米颗粒通过溶酶体包裹进入细胞; 通过超声微气泡辐照, 纳米颗粒能够 以更高效率通过非内吞途径直接传输进入细胞质而不被溶酶体包裹. 不同传输途径导致纳米颗粒分别进入溶酶体和细胞质, 造成对细 胞内氧化应激水平、总抗氧化能力以及谷胱甘肽过氧化物酶活性的响应不同. 综上研究表明, 超声微气泡介导的磁性纳米颗粒传输能 够成为一种高效无损的细胞纳米颗粒输运新方法, 同时通过控制纳米颗粒进入细胞质降低了纳米颗粒的毒性, 从而能够更广泛应用于 纳米生物医学的应用研究. 